\title{
Poor Vision and the Elderly-A Domiciliary Study
}

\author{
A. J. ELLIOTT \\ Norwich
}

\begin{abstract}
Summary
Thirty-four patients living in Norfolk, aged 65 years and over, with visual acuities between $6 / 60$ and counting fingers were interviewed at home to ascertain the degree of their disability and their use of low vision aids.

Visual acuity in this range was not associated with patients' mobility or their dependence on others. A threshold of useful vision could not be identified within this range.

Use of low vision aids, although disappointing, was more frequent by those who had attended a low vision clinic.
\end{abstract}

The relationship between visual acuity, visual ability and the disability that is produced by a reduction in these is an important but difficult area to study. One example of such difficulty is found in the statutory definition of blindness where the ability to do a job requiring sight is incorporated: a test of little relevance to the elderly. It would be useful to know if a threshold acuity existed which was associated with a significant increase in disability. Disability is hard to measure however, particularly in the elderly when other non-visual disabilities may predominate and in whom disabilities are often multiple. ${ }^{1}$ This study has concentrated on three factors which are related to disability but which are easier to measure. 'Engagement' refers to a person's ability to make good use of his or her time including hobbies, reading and television. 'Mobililty' is the ability to move around in the environment both within and away from the home, and 'Dependence' refers to reliance on friends, neighbours and organised help such as meals-on-wheels. Assessments of this nature are better made at home,$^{2}$ and an additional benefit of this was to find out whether patients really did use the low vision aid given to them by the hospital.

The study originally included all age groups, but the heavy skew towards the elderly suggested the eventual exclusion of those under 65 in order to make it more specific to the elderly poor sighted, and it is this group which is reported here.

\section{Patients and method}

Patients aged 65 years or older attending a general ophthalmology clinic at the West Norwich Hospital and whose corrected visual acuities were between $6 / 60$ and counting fingers (CF) in each eye, were invited to participate. Patients were visited in their own homes by the author and a structured questionnaire was used to assess their visual abilities, use of low vision aids, use of radio and television, and their dependence on community services and primary care. Ability to travel around and away from the home was assessed as was whether they made good use of their time i.e. enthusiasm for life or 'engagement'. A summary of the questionnaire is given in Table I.

From: The West Norwich Hospital, Norwich, Norfolk.

Correspondence to: A. J. Elliott, Senior Registrar in Ophthalmology, Department of Ophthalmology, Clinic 3, Addenbrookes Hospital, Hills Road, Cambridge CB2 2QQ 
Table I Summary of questionnaire used to assess patients at home

1 Visual ability: Questions about visually dependent tasks including reading of books and newspapers, telling the time and identifying money.

2 Use of radio and television.

3 'What do you miss most?'

4 Engagement assessment: how usefully time is spent, graded 1 to 5.

5 Mobility assessment: Ability to move around within and away from the home. Use of public transport. 'Do you ever go out?'

6 Dependence on other people. (Table II)

7 Possession and use of low vision aids.

8 Measurement of visual acuity for near and distance, with spectacles and low vision aids if available.

Table II Scoring system for mobility assessment

1 Poorly mobile within own home. Never goes out.

2 Manages well moving around at home but only leaves the house if relative takes him/her or if visit to day centre organised.

3 Reasonably mobile inside and away from home but unlikely to use public transport and would not fetch pension or go shopping.

4 Frequently uses shops and fetches pension. Frequently goes out to friends or social club.

5 Fully mobile including unaided visits on public transport to city (Norwich).

Table III Scoring system for dependence assessment

1 Manages well with no help even if living alone. May be providing support for another person e.g. spouse.

2 Manages well even if alone. Not reliant on outside help.

3 Manage reasonably well with regular but not daily help from friends, relatives particularly for shopping or heavy cleaning.

4 Highly dependent, if living alone, on regular help from relatives or social servics e.g. home-help, meals on wheels. May be in warden controlled accommodation.

5 In old peoples' home or highly dependent on spouse or relative e.g. living with daughter or son because failing to cope alone.

'Engagement', 'mobility' and 'dependence' were graded on a one to five scale (Tables II and III show guidelines for the latter). Corrected visual acuity for near and distance, and with a low vision aid if available was measured in the home.

\section{Results}

Thirty-four patients were interviewed and examined.

There were 16 men and 18 women, whose ages ranged from 67 to 88 years (mean 79.0). Principal diagnoses i.e., the sight limiting conditions of the better eye were as follows: disciform macular degeneration in 8 patients; nondisciform senile macular degeneration in 8 patients; diabetic maculopathy in eight; glaucoma in six; myopic degeneration in two; cataract in one; bilateral macular holes in one; and benign mucous membrane pemphigoid in one. One patient was included in both the glaucoma and disciform groups-apparently equally disabling in this case. Visual acuities in the disciform group were notably worse: six of 8 patients in this group were $1 / 60$ or less, compared to one of eight with macular degeneration and one of eight with diabetic maculopathy.

Scores for engagement, mobility and dependence are illustrated in Table IV. No significant effect of visual acuity on any of these scores was observed. The scores were also analysed according to principal diagnosis (Table V). Glaucoma patients had lower engagement scores than those with poor sight due to disciform degeneration ( $\mathrm{p}=0.04 \mathrm{Mann}$ Whitney), but the patient numbers are small. Otherwise no other associations with diagnosis were found. Neither did age or sex have a significant effect on engagement, mobility and dependence scores.

The dependence assessment revealed that 6 
Table IV Numbers of patients achieving stated engagement, mobility and dependence scores at four levels of vision

\begin{tabular}{|c|c|c|c|c|c|c|c|c|c|c|c|c|c|c|c|}
\hline \multirow[b]{2}{*}{ Visual acuity } & \multicolumn{5}{|c|}{ Engagement } & \multicolumn{5}{|c|}{$\begin{array}{c}\text { Scores } \\
\text { Mobility }\end{array}$} & \multicolumn{5}{|c|}{ Dependence } \\
\hline & 1 & 2 & 3 & 4 & 5 & 1 & 2 & 3 & 4 & 5 & 1 & 2 & 3 & 4 & 5 \\
\hline $\begin{array}{l}\text { Count fingers } \\
\text { or worse }\end{array}$ & 2 & 1 & 0 & 2 & 0 & 1 & 2 & 0 & 1 & 1 & 1 & 1 & 0 & 2 & 0 \\
\hline $1 / 60$ & 1 & 5 & 0 & 2 & 0 & 2 & 2 & 1 & 3 & 0 & 1 & 0 & 0 & 5 & 2 \\
\hline $2-4 / 60$ & 1 & 2 & 0 & 2 & 0 & 1 & 1 & 2 & 1 & 0 & 1 & 1 & 2 & 1 & 0 \\
\hline $6 / 60$ & 2 & 5 & 6 & 3 & 0 & 4 & 5 & 3 & 2 & 2 & 3 & 6 & 3 & 4 & 1 \\
\hline
\end{tabular}

Table $\mathbf{V}$ Numbers of patients achieving stated engagement, mobility and dependence scores by diagnosis

\begin{tabular}{|c|c|c|c|c|c|c|c|c|c|c|c|c|c|c|c|}
\hline \multirow[b]{2}{*}{ Diagnosis } & \multicolumn{5}{|c|}{ Engagement } & \multicolumn{5}{|c|}{$\begin{array}{c}\text { Scores } \\
\text { Mobility }\end{array}$} & \multicolumn{5}{|c|}{ Dependence } \\
\hline & 1 & 2 & 3 & 4 & 5 & 1 & 2 & 3 & 4 & 5 & 1 & 2 & 3 & 4 & 5 \\
\hline $\begin{array}{l}\text { Disciform } \\
\text { macular } \\
\text { degeneration }\end{array}$ & 0 & 4 & 0 & 4 & 0 & 2 & 2 & 0 & 2 & 2 & 2 & 1 & 1 & 3 & 1 \\
\hline $\begin{array}{l}\text { Senile macular } \\
\text { degeneration }\end{array}$ & 3 & 1 & 2 & 2 & 0 & 1 & 4 & 3 & 0 & 0 & 1 & 4 & 0 & 2 & 1 \\
\hline $\begin{array}{l}\text { Diabetic } \\
\text { maculopathy }\end{array}$ & 2 & 3 & 3 & 0 & 0 & 3 & 3 & 1 & 1 & 0 & 0 & 2 & 3 & 3 & 0 \\
\hline Glaucoma & 1 & 5 & 0 & 0 & 0 & 3 & 1 & 1 & 1 & 0 & 0 & 0 & 0 & 5 & 1 \\
\hline
\end{tabular}

patients had a home help, two had meals on wheels, four had regular visits by the district nurse, and three patients were on their general practitioner's regular visiting list. One patient was in an old people's home.

Of 34 patients, all but two had tried a low vision aid at some time. Thirty patients had such an aid in their possession at the time of the interview (of the two that did not one had been to a low vision clinic and one had not). Fifteen of 30 patients who possessed an aid had obtained this at a low vision clinic; the other fifteen had aids from other sources. All patients seen in the low vision clinic had been given at least a near vision aid i.e. none were

Table VI Number of patients using low vision aids

\begin{tabular}{|c|c|c|}
\hline & \multicolumn{2}{|c|}{ Source } \\
\hline & Low vision clinic & Elsewhere \\
\hline Never used & 5 & 12 \\
\hline Occasionally & 7 & 1 \\
\hline Often used & 3 & 2 \\
\hline
\end{tabular}

found unsuitable and later obtained an aid elsewhere. Frequency of use is shown in Table VI. Amalgamating of the 'occasional' and 'often' groups, the Chi squared test with Yates' correction shows that a hospital low vision aid is significantly more likely to be used $(p<0.05)$. Two of the failures in this group proved to be illiterate! There was no tendency for low vision aids to be less frequently used by older patients.

Fourteen patients took a newspaper for their own use $(41 \%)$ and there was a strong association with good near vision: eight of 14 patients taking a regular newspaper had a near vision N8 or better using an aid if available $(\mathrm{p}<0.005$, Chi square test with Yates' correction). Nineteen of the 20 patients who did not take a newspaper achieved a near acuity of N10 or worse. Use of a low vision aid was, as expected, correlated with taking a newspaper $(\mathrm{p}<0.001)$.

Only one patient ever borrowed books from the library, despite widespread availability of large print library books.

There was no association between visual 
acuity and a claimed inability to read a clock or watch $(47 \%)$, or a claimed difficulty with identification of money $(79 \%)$. In many homes the clocks were quite inappropriate with little contrast between the fingers and the face.

As expected, television and radio were commonly used. Use of each was recorded on a scale of one to four. Radio and television were used on an approximately equal basis. Variation in preference was not related to visual acuity in this range and specifically there was no significant tendency for those with poorer sight to use radio in preference to television.

Patients were asked what activity they missed most of all as a result of their visual loss. Only eight thought that reading was the most regrettable loss (four others rated reading second to some other loss). Three (two male, one female) missed driving, four missed gardening, two housework and eleven missed handwork including knitting, sewing and woodwork. One patient rated smoking as his most regrettable loss.

\section{Discussion}

Visual acuity in the $6 / 60$ to CF range could not be related to disability as assessed by the parameters studied here. There was no threshold acuity below which patients had markedly increased handicap. Yet low vision is considered to be a significant and often unnoticed handicap in the elderly, although if another disability is present it is more likely to be known to the medical services and some sort of help provided for $\mathrm{it}^{3,4}$. So if poor vision really is an important disability, why has this study failed to measure a social effect? Firstly it is possible that an effect has been swamped by other factors such as reduced mobility due to arthritis or general infirmity, or, for example, increased dependence due to chronic medical diseases including stroke, angina and diabetes. Secondly, visual acuities of CF or better may not be bad enough to cause a measurable effect, and central acuity gives no idea of peripheral visual field which is necessary for confident navigation. Nevertheless, one would expect that a gross central field defect would impair confidence to travel away from home. In a survey in Nottingham which sampled from a population of those registered blind or partially sighted a stated vision of better than perception of light was not associated with more frequent outings from the home. ${ }^{5}$ Unfortunately the Nottingham survey did not establish visual acuity in more detail.

This study could not and did not attempt to measure adaption to visual loss, and a well adapted person would score highly on this assessment, and their true disability (if it was still regarded as a disability) would be undetected or underestimated. A possible indicator of adaption was that few patients missed reading. However use of radio and television was not influenced by vision in this range where one might have anticipated an increased use of the radio in those with worse vision. Perhaps the dominance of television and radio for this generation has buffered the influence of poor reading vision particularly in old people who do not need sight for reasons of employment.

Although the infrequent use of low vision aids was disappointing, some did derive considerable benefit. There is more to low vision aids than magnifiers ${ }^{6,7}$ and it should be noted that this study did not assess application of other advice commonly given in low vision clinics such as lighting which is frequently inadequate ${ }^{8}$ Certainly these results support the principle that time spent ascertaining patients' needs and in explanation and encouragement is important in the low vision clinic.

If the threshold of useful vision is less than $\mathrm{CF}$, then this is particularly heartening and of practical importance to ophthalmologists faced with decisions about restoring limited sight e.g. when cataracts coexist with gross maculopathy and in 'only-eye' retinal detachment surgery: it is common anecdotal experience that even only little sight is worth having, a concept which is consistent with these results.

I gratefully acknowledge the help of Mrs Jane Paxon who runs the low vision aid clinic at the West Norwich Hospital, and Mrs Carol Wilson who typed the manuscript.

\section{References}

${ }^{1}$ Williamson J, Stokoe IH, Gray S et al. Old people at 
home: their unreported needs. Lancet 1964, 1: 1117-20.

2 Arcand $M$ and Williamson J. An evaluation of home visiting of patients by physicians in geriatric medicine. Br Med J 1981, 283: 718-20.

${ }^{3}$ Cullinan T. Visual disability in the elderly. London and Sydney. Croom Helm. 1986.

${ }^{4}$ Fenton PJ, Arnold RC, Wilkins PSW. Evaluation of vision in slow stream wards. Age Ageing 1975, 4: 43-8.

${ }^{5}$ Clark-Carter DD, Howarth CI, Heyes AD, Dodds AG, Armstrong JD. The visually handicapped in the City of Nottingham 1981: a survey of their disabilities, mobility, employment and daily living skills. Blind Mobility Research Unit, University of Nottingham.

${ }^{6}$ Silver J. Living without macular function: the optimum use of remaining vision. Semin Opthalmol 1986, 1: 146-52.

${ }^{7}$ Hillman JS. Aids for low vision in the elderly. $\mathrm{Br}$ Med $J$ 1988, 296: 102-3.

${ }^{8}$ Silver JH, Gould ES, Irvine D, Cullinan T. Visual Acuity at home and in eye clinics. Trans Ophthalmol Soc UK. 1978, 98: 262-9. 